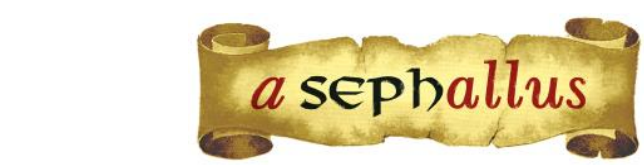

Revista aSEPHallus de Orientação Lacaniana

Núcleo Sephora de Pesquisa sobre o Moderno e o Contemporâneo

ISSN 1809 - $709 \mathrm{X}$

\title{
O olhar sem véu: transparência e obscenidade
}

Tania Coelho dos Santos

Pós-Doutorado no Département de Psychanalyse de Paris VIII; Professora Associada IV do PPG em Teoria Psicanalítica da UFRJ; Psicanalista, Membro da École de la Cause Freudienne, da Escola Brasileira de Psicanálise e da Membro da Associação Mundial de Psicanálise; Membro da Associação Universitária de Pesquisa em Psicopatologia Fundamental; Pesquisadora bolsista nível $1 \mathrm{C}$ do CNPq;

Presidente do Instituto Sephora de Ensino e Pesquisa de Orientação Lacaniana; Editora de aSEPHallus Revista de Orientação lacaniana.

E-mail: taniacs@openlink.com.br

Resumo: Minha tese é a de que vivemos uma torção e não uma ruptura entre a modernidade e a hipermodernidade. A hipermodernidade é o desmentido de que o Nome do Pai seja o agente da lei simbólica. Diferentemente do ensina Miller (2005) não me parece que vivemos na época do "Outro que não existe". Do meu ponto de vista, a afirmação de que "é proibido proibir", subverte a tese freudiana de que a neurose é o negativo da perversão. A fantasia perversa pode expressar-se a céu aberto. Se, como ensina Lacan, o objeto a ocupa a posição de agente no discurso (supereu) é porque a lei do mercado impõe o rebaixamento da dignidade da Coisa (Ding) aos objetos trocáveis, à mercadoria que se compra e se vende.

Palavras-chave: modernidade; hipermodernidade; Nome-do-Pai; Outro; supereu.

\begin{abstract}
My thesis is that we are experiencing a bend and not a break between modernity and hypermodernity which is a denial of the Name-of-the-Father as the agent of symbolic law. Unlike what is taught by Miller (2005) I do not believe that we are living in the age of the "non-existing Other". From where I see it, the traditional Brazilian saying from the seventies: "forbidding is forbidden" subverts Freud's thesis that neurosis is the negative of perversion. The perverse fantasy may be openly expressed. If according to Lacan's teaching the objet petit $a$ occupies the position of agent in the speech (superego) it is due to the fact that the market law forces the dignity of the Thing (Das Ding) to be debased to a tradable object, to a merchandise that can be bought and sold.
\end{abstract}

Key-words: modernity; hypermodernity; Name-of-the-Father; Other; superego.

Résumé: J'avance la thèse selon quoi ce que nous vivons est une torsion et non pas une rupture entre la modernité et I'hypermodernité, un démenti du Nom-du-Pére comme agent de la loi symbolique. Malgré l'enseignement de Miller (2005), je ne crois pas que nous sommes dans l'âge de "I'Autre qui n'existe pas". À mon avis, le dicton populaire brésilien des années soixante dix: "il est interdit d'interdire" est une subversion de la thèse de Freud qui définit la névrose comme la négation de la perversion. Le phantasme pervers peut être exprimé ouvertement. $\mathrm{Si}$, comme enseigné par Lacan, l'objet a occupe la position d'agent dans le discours (surmoi), c'est parce que la loi dum arché impose le rabaissement de la dignité de la Chose (Das Ding) aux objets échangeables, à de la marchandise qui peut être achetée et vendue.

Mots-clés: modernité; hypermodernité; Nom-du-Père; Autre; surmoi. 


\section{O olhar sem véu: transparência e obscenidade}

Tania Coelho dos Santos

\section{Nem modernos, nem pós-modernos}

Pós-modernidade, hipermodernidade ou contemporaneidade? Qual é o melhor termo para qualificar o tipo de laço social ao qual vamos nos referir neste artigo? O primeiro termo foi cunhado por J. F. Lyotard $(1986)^{1}$ e designa o advento do relativismo pós-científico. Guiddens (1991) não advoga um corte entre a modernidade e o período que a sucede, preferindo designá-lo como hipermodernidade. O termo contemporaneidade é mais difuso e designa o conjunto de transformações sociais, tecnológicas e econômicas do tempo em que vivemos. Prefiro o termo hipermodernidade porque minha tese é a de que vivemos uma torção e não uma ruptura. Minha tese é a de que a hipermodernidade é o desmentido de que o Nome do Pai seja o agente da lei simbólica.

É consenso entre os psicanalistas lacanianos que a imago paterna não é mais o semblante que regula o campo pulsional. O que é então que funciona como supereu em nossa hipermodernidade? De acordo com Lacan, quando formulou os quatro discursos, o objeto a pode ocupar o lugar do agente no discurso, nos sintomas e nos laços sociais. Neste caso, ele é um semblante que toma o lugar do Nome do Pai.

Neste artigo vamos apresentar duas interpretações do ensino de Lacan. A primeira é a seguinte. Diferentemente do ensina Miller (2005), não me parece que o Nome do Pai, semblante de um Outro consistente, declina em favor de um Outro inconsistente. Não me parece que vivemos na época do "Outro que não existe". A hipermodernidade - do meu ponto de vista - consiste no desmentido da função do semblante do Nome do Pai de agente da castração, de supereu. A afirmação de que "é proibido proibir", subverte a tese freudiana de que a neurose é o negativo da perversão. A fantasia perversa pode expressar-se a céu aberto. Não precisa mais ser recalcada.

A segunda é a seguinte. Quando o objeto a ocupa a posição de agente no discurso (supereu) é porque a lei do mercado impõe o rebaixamento da dignidade da Coisa (Ding) aos objetos trocáveis, sua redução à mercadoria que se compra e se vende. Todos os objetos entram no mercado. Até mesmo a intimidade e a dignidade de cada um, pode ensejar um exuberante mercado de imagens.

\section{O supereu hipermoderno}

Quando Lacan propôs comparar o pensamento do filósofo Kant com o de Sade, um libertino, extraiu o seguinte paradoxo sobre a lei moral: "o supereu é um imperativo de gozo". Kant nos convida a renunciar aos nossos objetivos egoístas para somente promover o soberano bem coletivo. Sade, ao contrário, defende o direito à satisfação absoluta de todos os nossos apetites mais egoístas. Um e outro advogam, respectivamente, o direito e o avesso da lei moral. Lacan conclui que com Kant, o moralista, quanto mais renunciamos à satisfação egoísta, mais precisaremos renunciar a ela. 
Freud formalizou este mecanismo, e o batizou de recalcamento da sexualidade. Com Sade, quanto mais gozamos, mais quebramos a cara. Freud abordou as consequências psíquicas devastadoras da destrutividade da pulsão de morte no último período de sua obra. O sentimento inconsciente de culpa pode conduzir a atos criminosos que satisfaçam a necessidade inconsciente de punição. $\mathrm{A}$ hipótese de que existe um princípio mais primitivo que o princípio do prazer, o conduziu a admitir que a pulsão de morte - e não o recalcamento da sexualidade - é a única a força responsável pelo sofrimento neurótico. Lacan conclui, entretanto, que a lei moral não nos deixa nenhuma saída. Ou renunciamos ao gozo e adoecemos de neurose, ou gozamos à vontade e destruímos a nós mesmos e aos outros.

Para Freud, diferentemente de Lacan, Kant e Sade não são equivalentes. Um não é o avesso do outro, tão pouco. A topologia de Freud supõe que haja uma hegemonia de um sobre o outro. Para Freud, a lei edipiana, se por um lado nos exige renunciar ao objeto absoluto do gozo, por outro nos permite usufruir de nossos bens, com os devidos limites. 0 imperativo categórico kantiano nos protegeria de nós mesmos e do pior, a pulsão de morte. O supereu arcaico, pré-edípico, é o vilão da saga freudiana. Cultura pura de pulsão de morte, abriga um imperativo que comanda sadeanamente a devorar o outro ou a se fazer devorar por ele. Tal como Kant, para Freud, a felicidade não é em si mesma um bem moral. Freud, assim como Kant, rejeitariam a moral hedonista que caracteriza nossa época.

Na modernidade, o imperativo categórico kantiano prevaleceu. A lei edipiana, a primazia do simbólico, o Nome do Pai, o mal-estar na civilização apaziguavam a ferocidade da pulsão e regulavam o usufruto do corpo e dos bens. A hipermodernidade me parece sadeana. $\mathrm{O}$ objeto do gozo ascendeu ao posto de comando e nos incita a gozar sempre mais, custe o que custar. $\mathrm{O}$ olhar, ora benevolente ora crítico do ideal do eu, na modernidade, comparecia sempre velado. Invisível, nos observava, nos corrigia ou nos encorajava. A instância do olhar nos contempla hoje à céu aberto. Vemos e somos vistos permanentemente. $\mathrm{O}$ olhar se dá a ver, não se esconde, se mostra.

\section{Do panoptismo ao reality show}

Gerard Wajcman (2011) afirma que estaria em curso uma mudança sem precedentes em nossa relação com o mundo, com nosso corpo e com nosso próprio ser. A hipermodernidade é a civilização do olhar absoluto. Há olhos por todos os cantos, extensões maquínicas do olho, "próteses do olhar". Esse deus onividente, onivoyeur, é fabricado com o auxílio da tecnologia. "Nós somos uma nova raça de voyeurs modernos. (...) Haveria uma ameaça pesando sobre o íntimo" (Wajcman, 2011, p. 44). "A guerra política do sujeito engaja-se nisso" (Wajcman, 2011, p. 51). "Ora, não se trata apenas de um conjunto frio de dispositivos e máquinas que nos examinam dia e noite. Podemos nomeá-lo também de o Olho Universal... Um desejo anima este olho" (Wajcman, 2011, p. 76). 0 inimigo para Wajcman é o discurso da ciência que se encarna em dispositivos científicos como câmeras de vídeo vigilância. 
Minha perspectiva é outra. O discurso da ciência não é um desejo autônomo de ver e saber. Penso que o discurso coletivo, autodenominado de politicamente correto, é absolutamente paranoico, não cessa de apontar supostas vítimas de preconceito ou violência e clama por mais e mais segurança, reparação, indenização e vigilância. Os indivíduos nesta sociedade do hipercontrole recíproco - segmentados em tribos - tornaram-se perigosos uns para os outros. Diferentemente de Wajcman, advogamos a tese de que o campo do olhar nos dias de hoje excede o domínio da vigilância. Na modernidade, o olhar panóptico exercia seu poder de vigilância, exame e disciplina, ao preço de ocultar-se. O mestre via sem ser visto. Hoje o olhar não é mais oculto, ao contrário, está a céu aberto. A vontade contemporânea de "tudo ver" é tirânica e nasce de um imperativo político - e não simplesmente científico - de transparência que atravessa e comanda toda a ordem social. Vigiar e ser vigiado é uma dimensão essencial da vida pública, quando vivemos divididos em tribos que se digladiam pelo direito ao gozo na cena social. Esta guerra por direitos, eleva ao zênite o direito absoluto à liberdade de expressão em detrimento do direito à privacidade. Em nome da liberdade de expressão, cresce a desconfiança paranoica em relação a todo e qualquer segredo, a tudo que é privado, a tudo que é percebido como íntimo. Basta observarmos a recente decisão do Supremo Tribunal Federal que legitimou a publicação de biografias sem que seja necessária a autorização do biografado. Quem achar que sua privacidade foi invadida que vá reclamar com o Juiz e exigir indenização. $O$ direito de bisbilhotar a vida alheia é mais importante do que o direito de preservar a própria imagem, privacidade e intimidade. Assim pensam nossos juízes. Mais uma vitória do discurso politicamente correto. O culto à privacidade individual ou familiar é perigoso. Serve para ocultar práticas criminosas, potencialmente danosas aos interesses de outros indivíduos ou grupos.

Os psicanalistas sabem muito bem que o gozo opaco não pode ser extinto. Por essa razão, advogo que o voyeurismo e o exibicionismo estão no comando. É mais uma prova da tese lacaniana da ascensão ao zênite da civilização do objeto $a$. A pulsão escópica nos governa. O gozo de ser visto acompanha o gozo de tudo mostrar, tudo exibir e tudo dar a ver, tudo bisbilhotar e tudo saber.

Para repensar os efeitos de poder, saber e prazer que o campo do olhar engendra nos dias de hoje, retornamos à tese de Foucault: a modernidade consiste num rebaixamento geral da lei simbólica à norma social. De acordo com Lacan (1973-1974, aula de 9/3/1974), no discurso da civilização contemporânea, o Nome do Pai foracluído do simbólico retorna no real das normas sociais. Interpretamos suas palavras no seguinte sentido: a metáfora como operador simbólico foi substituída pela norma social. $\mathrm{O}$ instrumento normatizador é muitas vezes a média estatística. $\mathrm{O}$ Nome do Pai, em nosso passado recente, orientava as identificações constituindo a instância psíquica do ideal do eu. Diferentemente do ideal do eu, o que prevalece hoje é a identificação ao pequeno outro como par ou como resto. Ou seja, é o privilégio do eu ideal, identificação narcísica ou, simplesmente, da pulsão condensada no resto autoerótico.

Os grupos de pares organizam-se como tribos em torno de uma identificação ao semelhante ou a um objeto de gozo. Há grupos constituído pelos gordos, pelos feios, pelos malhadores, pelos 
populares, pelos tímidos, pelos gays, pelos nerds, pelos viciados em videogame, enfim... Um novo imaginário manifesta-se no discurso politicamente correto, nova ordem de ferro, mais feroz do que a interdição pelo Nome do Pai. Em lugar de orientarem-se por um ideal do eu coletivizado, os indivíduos precisam discernir qual é o eu ideal que caracteriza o grupo ao qual pertencem. Nossa tese é: a cidade está tribalizada. Este novo imaginário é regulado pela intensificação da vigilância interativa entre os semelhantes, que zelam pela adequação de cada um à norma de sua tribo. As tribos reivindicam direitos iguais aos dos indivíduos de outras tribos. Às vezes, reivindicam o direito de serem tratadas como exceção e defendem-se acusando a sociedade de abuso, violência ou discriminação. Na era da absolutização do direito ao gozo é preciso vigiar e ser vigiado.

Em seu conhecido livro intitulado "Vigiar e Punir", Foucault descreve a extraordinária inversão da economia de visibilidade que se deu na passagem do Antigo Regime à modernidade. 0 poder majestático do rei manifestava-se na riqueza de suas vestes e no aparato exuberante de seus palácios e da corte que o cercava. A riqueza devia evidenciar a encarnação do poder divino em sua pessoa, aqui na terra. A arte de punir exemplarmente os criminosos, com a exibição pública de torturas bárbaras e demoradas, servia igualmente para demonstrar a assimetria de forças entre 0 soberano e seus súditos e desencorajar os parricidas e os regicidas. O olhar dos súditos capturado, hipnotizado pela exuberância do poder majestático, sujeitava-se ao soberano. O supereu, enquanto uma instância intrapsíquica, não existia, pois a consciência moral apresentava-se inteiramente externalizada, e seus efeitos de inibição sobre o comportamento potencialmente criminoso dependiam da duração na memória das imagens sedutoras ou aterrorizantes do poder real.

Segue-se à revolução francesa, o nascimento do Estado moderno. 0 poder que sujeita pela hipnose é substituído pelo olhar panóptico que vigia, controla, examina, previne e disciplina os corpos tornando-os úteis e dóceis. A economia de visibilidade se inverte. O cidadão comum se converte em objeto do olhar vigilante de um observador invisível refugiado em sua torre panóptica. $\mathrm{O}$ supereu e o ideal do eu, instâncias morais constituídas pelas identificações pós-edipianas, serão os herdeiros dessa inversão da economia de visibilidade. O sujeito que é olhado, também se olha, torna-se capaz de vigiar-se, recompensar-se ou castigar-se.

\section{Do supereu ao supersocial}

Retomando o ponto de partida. O princípio identificatório que fundava o supereu não é mais a exceção que falta à ordem simbólica. O sujeito, na civilização do gozo escópico, identifica-se com a subjetividade "média" que funciona como eu ideal de seu grupo narcísico. Aspira conformar sua subjetividade à norma ou ao consenso de seus pares. Por essa razão, vivemos na época dos comitês de pares. Os comitês são norm-ativos, fazem a norma. A verdade nasce do consenso entre pares. Toda tradição, herança simbólica e transcendência é suspeita de abrigar o segredo, o oculto, o oracular, e conspirar contra a vontade ardente de perfeita simetria intersubjetiva e transparência 
absoluta. Por isso dizemos que em lugar do supereu, instância psíquica inconsciente e intrasubjetiva, vivemos na época do supersocial.

Passemos então ao paradoxo do gozo em jogo na inflação da vigilância na contemporaneidade. O sujeito que vigia não é mais, talvez, aquele que é observado por uma instância crítica internalizada, o supereu pós-edípico. Se ele vigia seus pares e é vigiado por eles, é porque a consciência moral está situada do lado de fora, na rede de olhares que se espreitam. A chamada sociedade do controle e da prevenção, com suas câmeras de vigilância 24 horas, não esconde o quanto as nossas cidades se tornaram hostis e perigosas.

Observa-se que na falta de uma instância intrapsíquica, de um supereu que regule a distinção entre privado e público, a barreira do pudor se desmancha. A intimidade dos casais tem sido um assunto recorrente na internet. A nova mania do selfie, no Instagram, são as imagens dos casais após o sexo, seguidas pela hastag \#aftersex. Este material, anteriormente escondido, agora é exibido e compartilhado nas redes sociais. O gozo de tudo ver e mostrar, atualmente, vem sendo reivindicado como um direito. Até onde se pode dizer que algo é obsceno diante da naturalidade com que a pornografia vem circulando na atualidade? Se o consumo de pornografia estava restrito à sexualidade masculina, agora ele se estende às mulheres e aos adolescentes também. Não se vê mais a dissimetria do gozo de homens e mulheres.

\section{0 desejo de exibir-se ao final da análise: testemunhos}

Em nossa comunidade, a dos psicanalistas de orientação lacaniana, também estamos atravessados pelo desafio de formalizar os princípios dessa nova subjetividade, disposta a tudo para "ver" e para se fazer ser "visto". Foi um passo importante pensar os efeitos da nova cultura do narcisismo sobre os finais de análise. Miller (2014) aposta que os testemunhos de passe hoje provam que o sintoma/castração (inconsciente/desejo) foi substituído pelo sinthoma/pedestal (narcisismo/sublimação). Esta aproximação da sublimação com o narcisismo é alguma coisa relacionada com a época do falasser. Miller (2010, p. 186) dizia: "Eu diria até que seria necessário que uma análise leve ao desejo de se exibir, quer dizer que o passe tem alguma coisa do desejo do ator".

O testemunho público do que uma análise revela de mais íntimo e mais êxtimo à subjetividade de cada um, deve nos ajudar a rever nossas posições acerca do gozo escópico na contemporaneidade. $O$ que é que nós, psicanalistas de orientação lacaniana, queremos provocar no público quando deitamos sobre ele uma verdadeira enxurrada de narrativas sobre a experiência do inconsciente no divã. Demonstrar que o inconsciente não é íntimo? Demonstrar que neste terreno também não há mais nada de que se envergonhar? Mostrar ao público que os analistas são gente como todo mundo, com seus traumas, sintomas, angústias e inibições? Mostrar que não é mais preciso temer a assimetria de lugares de analisando e analista, que se experimenta no divã? Tratase de democratizar a relação entre analisando e analista? 
Porque a política do passe foi levada a introduzir a experiência do divã no circuito do gozo com o olhar? Foi a vontade de ver e saber o que anima a ciência, a motivação mais profunda? Sabemos que o gosto hipermoderno pela avaliação generalizada, como já desenvolvi anteriormente (Coelho dos Santos, 2010), propaga a nova "ordem de ferro", ditadura da transparência do sujeito a si mesmo e aos seus pares na civilização. O direito ao segredo, à privacidade, à esfera íntima, cede seu lugar ao imperativo de mostrar. A realidade psíquica é chamada a exibir-se no reality show dos meios de comunicação. Parece que a face de gozo do avaliacionismo é o crescimento do gosto pela exibição de si. Um questionário pode ser vivido como uma versão de uma entrevista concedida a um especialista. São difundidos na mídia padrões duvidosos de normalidade, engendrados por um discurso psiquiátrico menos semiológico e mais epidemiológico, em que a ideia de "homem médio" serve para produzir consenso social.

Sabemos muito bem que Freud ousou incluir a esfera mais íntima do sujeito no campo da Weltanschauung científica. A perspectiva cientifica lhe permitiu ampliar o campo do que se entendia até então por subjetividade para incluir nele o universo desconhecido das pulsões e do inconsciente. Vivemos hoje sob a ditadura de falar de si, mostrar-se, confessar-se. Freud foi o primeiro a comandar que se diga tudo mediante a regra fundamental da psicanálise. Mandamento impossível! Ele sabia colher o lapso, a hiância, a falha que se opunha ao cumprimento dessa injunção. Ele nos ensinou a reconhecer o sujeito, aí onde se manifesta, sempre velado, o desejo inconsciente. Por essa razão, não existe uma teoria do final de análise em Freud. A análise é interminável, tanto quanto o desejo é sempre velado. Para Lacan, diferentemente, toda análise é didática, pois a transmissão de um saber suposto e singular sobre o inconsciente conduz, sempre que a experiência é levada até o fim, à travessia do fantasma e à produção de um analista. $O$ passe é um dispositivo inventado por Jacques Lacan com a finalidade de verificar se o testemunho de um analisando demonstra que ele atravessou o fantasma fundamental e chegou ao final de sua análise.

O dispositivo do passe, primeiramente definido como atravessamento do fantasma, foi redefinido por Miller (2010) como uma mutação no campo do gozo. O dispositivo do passe foi primeiramente um instrumento para-universitário (Miller et al., 1997), pois tem uma afinidade de estrutura com o relatório de tese para uma banca. Tratava-se da demonstração e da verificação de um possível final de análise. Um analista precisaria fazer um esforço a mais - teórico e científico de construção de seu próprio caso.

\section{A intimidade tornou-se uma mercadoria?}

Se o padrão nos dias de hoje é o desejo de exibir-se, desejo de ator, será que podemos concluir que a esfera íntima entrou no mercado, tornou-se mais uma mercadoria que se compra e se vende no facebook? E nós analistas? Inventamos o nosso próprio Big Brother?

O tema da redução da intimidade à forma mercadoria é, sem sombra de dúvida, uma questão intrigante para nós analistas. Afinal, Marx demonstrou que o advento do capitalismo consistiu em 
reduzir a força de trabalho a uma mercadoria que se compra e que se vende. $O$ trabalho foi completamente dessacralizado e perdeu a dignidade de seus laços com a família e as corporações. Lacan (1968-1969) em seu comentário acerca dos acontecimentos de maio de 1968 na França, profetizou que a ascensão do valor do diploma universitário equivaleria a reduzir o saber a uma mercadoria que se compra e que se vende. Em nossa época, quando a intimidade se torna mais uma mercadoria e cai na rede social, já podemos dizer que também ela se submeteu à lei do mercado. Precisamos observar como é que a política do passe, com a divulgação para auditórios cada vez maiores de fragmentos da análise dos analistas, pode alimentar a construção dessa nova dimensão hiperexibicionista da subjetividade na hipermodernidade.

\section{O Outro não existe ou o Outro é lei do mercado?}

Volto ao ponto de partida. É consenso entre os analistas de orientação lacaniana a adesão à tese de que com o declínio do Nome do Pai - significante de que o Outro (Deus) existe - entramos numa era em que o Outro não existe. Desde o advento da modernidade, a exclusão de Deus do mundo, o advento da razão científica e a fundação do Estado laico são alguns indicadores da perda de consistência do Outro da religião. Lacan formalizou esta época da pluralização dos Nomes do Pai com o matema S( $\not$ $)$. Época de errância, de descrença e de redução do Outro a um mero semblante, de desmaterialização acelerada do sentido do real. De acordo com Miller (1996), entramos na época lacaniana da psicanálise. O relativismo pós-moderno conduz a uma pluralização das identificações na sociedade que discute, delibera por meio de seus comitês de ética. A debilidade mental generalizada e a angústia do desamparo na ausência de certezas são os índices da desconexão do Outro.

Essa abordagem da nossa época tem seu mérito. O desbussolamento, a invenção incessante de soluções solitárias para a falta de um ideal coletivo, a pregnância crescente do contágio identificatório pela influência dos meios de comunicação, tudo isso demonstra a tese de que o Outro pluralizou-se. É uma análise fundada no deslocamento político do regime monárquico para o regime democrático. Apoiada na construção lacaniana dos quatro discursos, a tese do Outro que não existe reside numa elaboração acerca do deslocamento do conceito do Nome do Pai para o conceito de $S_{1}$ (significante mestre ou enxame de significantes). O enxame contrapõe-se à exceção. Em lugar do significante do Nome do Pai, que designa o lugar de exceção ao conjunto - e que lhe empresta sua consistência por permanecer fora dele -, temos a pluralização dos significantes equivalentes entre si. Dufour (2005) pergunta: "o Mercado não está, em nossos tempos neo-liberais, no ponto de se constituir como novo grande Sujeito?" (Dufour, 2005, p. 75). Prossegue constatando que a narrativa que glorifica a mercadoria é provavelmente a narrativa dominante atualmente. Com a relativização absoluta promovida pelas narrativas do Estado-nação, a mercadoria, assim como os capitais, com efeito, deve poder circular sem fronteiras. A mercadoria deve poder funcionar sem fronteiras também na economia pulsional. $\mathrm{O}$ desejo sem objeto de cada um deve encontrar um objeto industrializado, 
customizado, sob medida, perfeitamente adequado à fantasia de cada consumidor. Como a satisfação absoluta é impossível, o enfado reconduz o consumidor à demanda e retroalimenta o mercado.

Dufour salienta que com o Mercado em sua forma atual, ampliado a todas as atividades humanas, chegamos ao apogeu de um processo que Adam Smith identificou pelo termo "mão invisível". A conotação religiosa deste termo que designa a lei do mercado não escapa a nenhum leitor atento. O mercado é o novo Deus. Ele apregoa que cada um deve perseguir livremente a satisfação de seus interesses egoístas pois, deste modo, o interesse coletivo da sociedade será alcançado. Este milagre se produz graças à mão invisível que regula tudo, substituindo a Providência divina em suas obras. 0 mercado somente obedece à lei interna que busca escapar a todo controle externo. E que lei é essa? De acordo com o autor é a da produção de quantidades de mercadoria cada vez maiores a custos cada vez menores. O mercado deve criar novos usos da mercadoria, chegando a passar para seu controle as esferas até então regidas por relações comunitárias, interpessoais, sexuais e geracionais.

\section{Abordagem do capitalismo hipermoderno: discurso ou rede?}

Uma análise mais cuidadosa do deslocamento da lei do mercado do capitalismo moderno até o capitalismo financeiro de nossos dias, requer, segundo me parece, migrar da noção de discurso para a noção de rede. $O$ discurso do mestre, matriz das três outras variantes (histérica, universitário e do analista), nada mais é do que a formalização do complexo edipiano. Ao Nome do Pai corresponde a letra $S_{1}$. Ao desejo da mãe, a letra $S_{2}$. Ao lugar do sujeito, a letra \$. A letra a, escreve o gozo, submetido à operação de recalque. O gozo incestuoso, ou impossível, deve ser recusado para que possa submeter-se à lei do desejo e colocar-se em discurso. É uma lógica da falta-à-ser.

A lógica da rede é diferente. Ela não supõe nenhum terceiro, a alteridade da exceção, o Nome do Pai. Tudo na rede encontra-se no mesmo plano horizontal, não há mais exterioridade nem interioridade, nem transcendência nem imanência. O ternário edipiano deu lugar à relação dual. Devemos tomar isso como contratos intersubjetivos que não precisam referir-se a nenhum universal. Todo conflito não passa de um desfuncionamento das relações duais que pode ser corrigido por meio de regulações sempre locais (por meio da norma, e não mais da lei). As interações não precisam levar em conta nem a diferença sexual, nem a diferença geracional, pois a origem e o fim da aventura humana não interessam a mais ninguém. A rede, segundo Dufour, constitui uma espécie de grau zero da sociedade, já que ela foraclui toda relação com o ser. 0 modelo da rede nos faz passar de um regime em que o inconsciente se manifestava de maneira prevalente pela neurose (como dívida para com o terceiro) para um modo em que ele se manifesta por formas aparentemente psicotizantes na pós-modernidade.

Sem dúvida, a configuração do sintoma na hipermodernidade nos exige desvendar a estrutura do supereu que os sustenta. É inútil insistir sobre a tecla de que tomam a forma de 
modalidades compulsivas de gozo fora do sentido e que resistem a toda abordagem pela via da interpretação. Se minha hipótese é correta, trata-se sempre do desmentido da castração. Um mesmo e monótono repercutir do libelo: "é proibido proibir". Eco da máxima sadeana: "tenho o direito de gozar do seu corpo, pode me dizer qualquer um, e exercerei esse direito, sem que nenhum limite me detenha no capricho das extorsões que me dê gosto nele saciar" (Lacan, 1998, p. 780).

O sentido do sintoma nos dias de hoje é determinado pelo discurso egoísta e hedonista que faz a apologia do direito a um gozo que não seja limitado pela lei da castração. Interpretá-lo é nada menos que elucidar sua estrutura, pois a pulsão é a parceira do supereu hipermoderno, tanto quanto o desejo é o parceiro do supereu moderno. Tudo se reduz a saber quem é o terceiro, deus ou o diabo? Qual é o imperativo que está no comando? O ideal ou o objeto $a$ ?

\section{Nota:}

${ }^{1}$ Também os seguintes autores, opõem a modernidade à pós-modernidade: M. Featherstone (1995), T. Engleton (1996), B. Smart (1993) Z. Bauman (1997), F. Jameson (1997), S. Connor (1989), D. Harvey (1989).

\section{Referências Bibliográficas}

Bauman, Z. (1997). O mal-estar da pós-modernidade. Rio de Janeiro: Zahar.

Brousse, M.-H. (2009, set.). A psicose ordinária à luz da teoria lacaniana do discurso. In Latusa digital - Revista da Escola Brasileira de Psicanálise, Seção Rio de Janeiro, 6(38). Recuperado de: http://www.latusa.com.br/pdf latusa digital 38 a1.pdf.

Canguilhem, G. (1978). O normal e o patológico. Rio de Janeiro: Forense-Universitária.

Castel, R. (1981). A gestão dos riscos. Rio de Janeiro: Francisco Alves.

Coelho dos Santos, T. (2010, mai.-out.). Ditadura da homogeneidade ou direito ao gozo autista do sinthoma? In aSEPHallus - Revista de Orientação Lacaniana, 5(10). Recuperado de: http://www.isepol.com/asephallus/numero 10/atualidades.html.

Coelho dos Santos, T. (2013, jul.-dez.). A psicanálise é uma ciência e o discurso analítico é uma práxis? In: Revista Ágora - Estudos em Teoria Psicanalítica, 16(2). Recuperado de: http://www.scielo.br/pdf/agora/v16n2/v16n2a08.pdf.

Coelho dos Santos, T. (2014). Responsabilidade coletiva ou responsabilidade subjetiva: a saúde é um direito ou um dever? In Barros R. M. M e Anciães V. Psicanálise e saúde: entre o sujeito e o Estado. Rio de Janeiro: Cia de Freud.

Coelho dos Santos, T. (2014). Do sujeito sujeitado à lei simbólica à normatividade do supersocial. In Coelho dos Santos, T. et al (Orgs.). Os corpos falantes e a normatividade do supersocial. Rio de Janeiro: Cia de Freud.

Connor, S. (1993). Cultura pós-moderna: introdução às teorias do contemporânea. São Paulo: Loyola. 
Engleton, T. (1998). As ilusões do pós-modernismo. Rio de Janeiro: Zahar.

Ewald, F. (1993). Foucault, a norma e o direito. Coleção Comunicação e Linguagens. Lisboa: Vega.

Fenichel, O. (1996). Teoria psiconalitica de las neurosis. Buenos Aires: Paidós.

Fonseca, M. S. (2013). A época da norma. In Revista Cult, 134. Recuperado de: http://www.revistacult.com.br.

Foucault, M. (1976). Histoire de la sexualité, la volonté de savoir. Paris: Gallimard.

Freud, S. (1974). Sobre o narcisismo: uma introdução. In J. Salomão (Trad.) Edição standard brasileira das obras psicológicas completas de Sigmund Freud (Vol. 14). Rio de Janeiro: Imago (Trabalho original publicado em 1914).

Freud, S. (1974). Os instintos e suas vicissitudes. In J. Salomão (Trad.) Edição standard brasileira das obras psicológicas completas de Sigmund Freud (Vol. 14). Rio de Janeiro: Imago (Trabalho original publicado em 1915).

Freud, S. (1976). Conferência XXXIV: Explicações, aplicações, orientações. In J. Salomão (Trad.) Edição standard brasileira das obras psicológicas completas de Sigmund Freud (Vol. 22). Rio de Janeiro: Imago (Trabalho original publicado em 1933).

Freud, S. (1975). Análise terminável e interminável. In J. Salomão (Trad.) Edição standard brasileira das obras psicológicas completas de Sigmund Freud (Vol. 23). Rio de Janeiro: Imago (Trabalho original publicado em 1937).

Giddens, A. (1991). As consequências da modernidade. São Paulo: UNESP.

Harvey, D. (1998). Condição pós-moderna. São Paulo: Loyola.

Jameson, F. (1997). Pós-modernismo: a lógica cultural do capitalismo tardio. São Paulo: Ática.

Lacan, J. (1998). Kant com Sade. In V. Ribeiro (Trad.) Escritos. Rio de Janeiro: Zahar (Trabalho original publicado em 1937).

Lacan, J. (1988). O seminário, livro 7: a ética da psicanálise. Rio de Janeiro: Zahar (Trabalho original publicado em 1959-1960).

Lacan, J. (1998). A ciência e a verdade. In V. Ribeiro (Trad.) Escritos. Rio de Janeiro: Zahar (Trabalho original publicado em 1965-1966).

Lacan, J. (2003). Joyce, o sinthoma. In V. Ribeiro (Trad.) Outros Escritos (pp. 560-566). Rio de Janeiro: Zahar (Trabalho original publicado em 1975).

Lacan, J. (2007). O seminário, livro 23: o sinthoma. Rio de Janeiro: Zahar (Trabalho original publicado em 1975-1976).

Lacan, J. Le séminaire, livre XIX: les nos dupes errent. Inédito. (Trabalho original publicado em 1973-1974).

Lyotard, J.- F. (1986). O pós-moderno. Rio de Janeiro: José Olímpio.

Matet-Lazarus, C. (2012). Rapport de la commission de la passe 2010-2011 (A10-B10). Paris: École de la Cause Freudienne. 
Miller, J.-A. (1994). Comment finissent les analyses. Collection du Champ Freudien. Paris: Seuil.

Miller, J.-A. et al. (1997). Le conciliabule d'Angers. Paris: Agalma/Seuil.

Miller, J.-A. (2003). La experiencia de lo real en la cura psicoanalitica. Buenos Aires: Paidós.

Miller, J.-A. (2005, nov. a 2006, abr.). A era do homem sem qualidades. In aSEPHallus - Revista de Orientação Lacaniana, 1(1). Recuperado de: http://www.isepol.com/asephallus/numero 01/traducao.htm.

Miller, J.-A. (2009). Nous sommes poussés par des hasards à droite et à gauche. In La Cause Freudienne, (71). Paris: Navarin.

Miller, J.-A. (2010). Le désir de nommer. In Miller, J.-A. (Org.). Conversation sur la passe: textes introductifs. Supplément de la Lettre Mensuelle. Paris: ECF.

Miller, J.-A. (2010a). Perspectivas do Seminário 23. O Sinthoma. Rio de Janeiro: Zahar.

Miller, J.-A. Haveria passe? (2010b, mai.-out.). In aSEPHallus - Revista de Orientação Lacaniana, 5(10). Recuperado de: http://www.isepol.com/asephallus/numero 10/traducao1 revista10.html.

Miller, J.-A. (2011). Perspectivas dos escritos e dos Outros escritos de Lacan, entre desejo e gozo. Rio de Janeiro: Zahar.

Miller, J.-A. (2014). L'inconscient et le corps parlant. Recuperado de: http//www.wapol.org/Template.asp.

Quetelet, A. (1991). Sur l'homme et le développement de ses facultes. Paris: Arthème-Fayard (Trabalho original publicado em 1835).

Sennett, R. (2000). A corrosão do caráter: consequências pessoais do trabalho no novo capitalismo. São Paulo: Record.

Smart, B. (1993). A pós-modernidade. Coleção Biblioteca Universitária, publicações EuropaAmérica, Portugal.

Wajcman, G. (2011). L'Oeil absolu. Paris: Denoel.

Citacão/Citation: Coelho dos Santos, T. (mai. a out. 2015). O olhar sem véu: transparência e obscenidade. Revista aSEPHallus de Orientação Lacaniana, 10(20), 4-15. Disponível em www.isepol.com/asephallus. doi: 10.17852/1809-709x.2019v10n20p04-15

Editor do artigo: Tania Coelho dos Santos.

Recebido/Received: 02/11/2015 / 11/02/2015.

Aceito/Accepted: 24/11/2015 / 11/24/2015.

Copyright: (C) 2013 Associação Núcleo Sephora de Pesquisa sobre o moderno e o contemporâneo. Este é um artigo de livre acesso, que permite uso irrestrito, distribuição e reprodução em qualquer meio, desde que o autor e a fonte sejam citados/This is an open-access article, which permites unrestricted use, distribution, and reproduction in any medium, provided the author and source are credited. 